\title{
Pioneering Sand Motor
}

The Sand Motor as

source to rethink

anthropogenic coastal

modifications in cultural

public space

\section{Jacqueline Heerema}

Satellietgroep, artists collective 


\section{Abstract}

Now that people all around the world are slowly starting to rethink how humanity and the planet are interrelated, new questions have arisen around the understanding of time and the perception of place. It's not merely a technical or a political challenge that we are facing, it is also a cultural one. The Sand Motor - as the first of its kind - uses the forces of the wind and waves as active agengies of change, but can it be valued as a driving force for humanity to change as well?

Drawing from primary artistic research of the sea, coastal transitions, climate change and human appropriations in The Netherlands and abroad, we can state that the ephemeral nature of the Sand Motor itself challenges a polyphonic discourse for co-creation of experiential knowledge. The Sand Motor can be perceived as a man-made intervention in public space, an openair, publicly accessible research site. Over the past 10 years, Satellietgroep redefined the Sand Motor as a cultural phenomenon, connecting the Sand Motor to the realms of art, culture, and heritage. This essay discusses a series of human-inclusive art projects, in which the Sand Motor evolves from a non-place into a vital learning environment for the cross-pollination of ideas and experimentations to rethink culture and nature. They demonstrate that pioneering with the Sand Motor should include pioneering with the social and cultural values of this artifact, not only to raise public and professional climateconsciousness, but also to adopt it as a human-inclusive landscape. This may well be the most underestimated value of the Sand Motor itself, and of the concept of Building with Nature in general.

\section{KEYWORDS}

Art, polyphonic discourse, co-creation of experiential knowledge, vital learning environment, public climateconsciousness 


\section{Introduction}

The Dutch have a rich cultural and innovative relationship with the sea. The ongoing existential challenges due to the fluxes of the North Sea in past, present and future are important for everyone. Shores can be perceived as thresholds of liminality. In time and space, the narratives of pre-human nature meet the narratives of humanity. To spark our imagination for an unforeseen future we are challenged to enhance professional and public climate-consciousness.

The Dutch artists collective, Satellietgroep (The Hague, 2006), redefined the Sand Motor as a cultural phenomenon (Satellietgroep 2007, 2008, 2013a, 2013b). With the Sand Motor, all issues around climate change, relative sea level rise, the future of coastal safety, and the role of humanity in these processes come together. The transdisciplinary collective creates conditions for artists, designers and students to work on-site during artist-in-residency programs, collaborate with the extensive network of locals and scientists - including the researchers of the NatureCoast program - and develop new works and insights that are shared with wider audiences during public programs, often beyond the realm of the arts. (Satellietgroep \& Heerema, J., 2019)

In retrospect, these reciprocal encounters revealed unforeseen values of the Sand Motor. It did not exist, and it will dissolve. We may argue that the ephemeral nature of the Sand Motor itself challenged a polyphonic discourse for the co-creation of experiential knowledge. In that sense, the Sand Motor evolved from a non-place (Augé, 1992) into a vital learning environment for the cross-pollination of ideas and experimentations to rethink culture and nature.

Sixteen Public Expeditions, a growing Sand Motor Collection, and an exhibition program called 'Climate as Artifact' (Satellietgroep, 2018) demonstrate how an explorational artist-in-residency program and an inclusive public program can create alternative ways of perceiving and being at the Sand Motor. This essay draws from pioneering with the Sand Motor and beyond, from tasting Fossils Soup to designing an educational Sand Motor visitor centre. Without judgement, without a preconceived idea, Satellietgroep is curious to see the opportunities that climate (change) can offer us. 


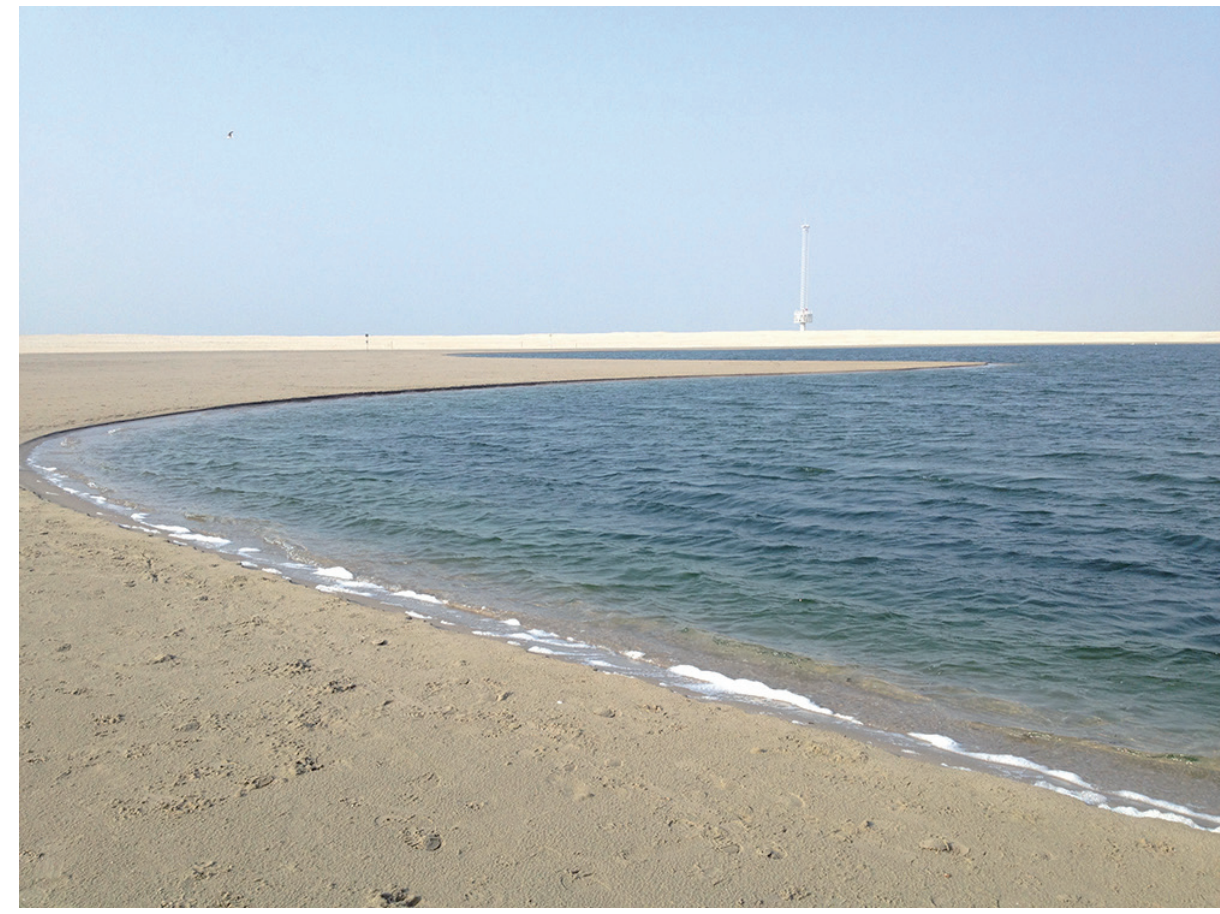

Figure 1. Sand Motor, 'The Dutch are masters in disguising a cultural landscape as a natural one. We tend to design, construct, reconstruct nature to fit our needs', quote and photo Jacqueline Heerema.

\section{Public climate-consciousness}

Now that people all around the world are slowly starting to rethink how humanity and the planet are interrelated, new questions arise around the understanding of time and the perception of place. It's not merely a technical or a political challenge that we are facing, it is a cultural one. People cherish the idea of what nature is and what the world should look like; our environment is adjusted to fit that image. Are we aware of this ongoing representation of nature? We manipulate biotopes and interfere with living and non-living ecosystems. We design parks, zoos, and aquariums. Do we still have a choice of how natural our human habitats can be?

In an insightful range of paleogeographic maps, Peter Vos reconstructs 'The Origin of the Dutch Coastal Landscape' since the Holocene, 11.000 years ago with the fluxes of the North Sea and the genesis of the coastal landscape, including the interactions between natural and anthropogenic (human-induced) processes. (Vos, 2015)

Geology meets archaeology on the shores of the oldest dune landscape in the Netherlands along the seashore, called Solleveld. Historical geographer, Jan Neefjes describes in the 'Landscape biography of National Park Hollandse 
Duinen': "In prehistory and early Middle Ages, the coastal landscape was one of the most densely populated areas of the Netherlands. In the design and development of the area, people used the complex of beach barriers and plains. Although this undeveloped dune area looks natural and natural processes are given space, people have left their mark on the dune landscape through deforestation, planting of helm grasses, agricultural use or for hunting." (Neefjes, 2018)

With the innovative construction of the Sand Motor on the foreshore of Solleveld, millennia of building with nature transformed into Building with Nature (written with capitals). The Sand Motor uses the forces of the wind and waves as active agencies of change, but can it also be valued as a driving force for humanity to change?

Before the public opening up of the Sand Motor on November 24 in 2011, Satellietgroep proposed to the main stakeholders of the Sand Motor (Province of South Holland and the Ministry of Infrastructure and Environment) to develop a consistent public cultural education program on and about the Sand Motor: "The Sand Motor is not only a unique example of Dutch innovative coastal management, but is also important for a wider audience. The upcoming public opening is an excellent moment to start to investigate what impact this coastal transition will have on people, communities, and the changing environment. The accessibility of the learning process of the Sand Motor is of public interest, for now and for the future, when the Sand Motor is added to the history books of school children."

This cultural vision requires that we tell the whole story. The Sand Motor is a pilot project to generate knowledge for future coastal protection, instigated by ongoing coastal erosion. Despite what most people think, the Sand Motor itself is not built to protect the Dutch coastline, it is an open-air, publicly accessible research site. Meanwhile, it is mostly promoted by the main stakeholders as a place where people "can experience and enjoy nature". The man-made aspect was more or less ignored as soon as the Sand Motor was built. Thus, people are excluded from what is actually happening in public space. With ongoing climate change, interventions in the coastal landscape will increasingly influence choices for a safe and healthy living environment. As Stephen Mintern wrote in 'The Sand Engine as a Productive Void. Discussing the Spatial Value and Public Appropriation of the Sand Engine' (Mintern, 2011), the Sand Motor is "the first of its kind (...), (which) means that the public have no pre-existing idea of how to occupy the space, it is a space void of any memory, therefore allowing for new more singular interactions with the space." If we follow this line of thought, we can conclude that we have to find new ways of interacting with our environment, thus creating new narratives. 
Public Expedition Zandmotor\#2 Cultural Geology, March 2015

"Through a nebulous sandstorm in which the entire surface of the landscape seemed to be on the move, a group of determined travellers slowly became visible. They have set out on an arduous journey leaving the mainland behind. Like the early travellers moving north after the receding ice of the last glacial maximum or 'iceage', they were moving into new territory. Our group was stepping onto the same sand that formed an area called Doggerland that once connected Holland and the UK but disappeared beneath the waves of the North Sea thousands of years ago. Some 21,5 million cubic meters of sand have now been brought up mechanically, to shape a temporary landscape: The Sand Motor." In his publication 'Next Doggerland', artist-in-residence Theun Karelse "contemplates the parallels and differences between the last climate change event and the current one, in terms of ecology and culture and explores what a positive agenda for the future could mean. How can humans contribute to a healthy and functioning landscape, that includes us? How can people, their technologies, and infrastructures become symbiotic partners in the landscape? What is this post-natural landscape?"

Karelse offers the audience 'Fossils Soup', a culinary experiment that seeks to connect with the ice-age relicts through a direct sensory experience.

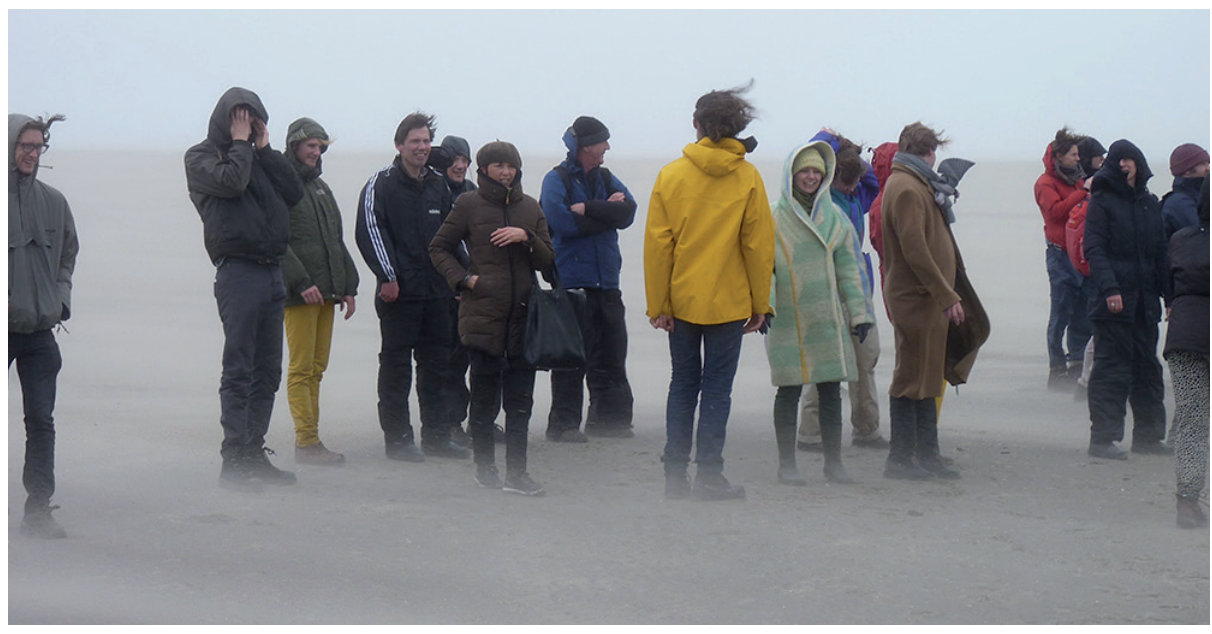

Figure 2. Public Expedition Zandmotor\#2 Cultural Geology, March 2015, photo Theun Karelse.

\section{The becoming of Sand Motor}

In January 2006, awareness that the North Sea may be perceived as a construction site or energy landscape to fit our needs instigated artists collective Satellietgroep to question 'To whom belongs the sea?' The initiative was triggered by the remarkable lack of involvement of arts, culture and heritage in the master plans for coastal transitions in The Netherlands, especially in The 
Hague, with top down reconstructions for urban beach resorts in Scheveningen and Kijkduin, and with the prospect of islands in front of the coast. Prospects of innovative engineering that raise questions about modifying public cultural space.

The Dutch word 'kunstwerk' has a double meaning: it can refer to a man-made infrastructure (like a dike, polder, Sand Motor) or to an artistic expression, called a work of art. In the 17th century, painters travelled to The Netherlands, in search of 'Dutch Light'. Pieter-Rim de Kroon and Maarten de Kroon made the international awarded documentary called 'Hollands Licht' (Dutch Light, 2003): "There's an ancient myth that the light in Holland is different from anywhere else, but it has never been put to the test. It's the light celebrated in paintings - in landscapes by Jan van Goyen and Jacob van Ruisdael, and in interiors and still lifes by Johannes Vermeer, Pieter Saenredam and Willem Claesz Heda. It's also in the works of later artists such as Jan Weissenbruch, Willem Roelofs, Paul Gabriël and Piet Mondriaan. It's the idea that light and observation were the cornerstones of a visual culture dating back to the 17th century. The German artist. Joseph Beuys, however, says that it lost its unique radiance in the 1950s, when the Dutch reclaimed the IJsselmeer (former Zuiderzee), bringing an end to a visual culture that had lasted for centuries."

Proposals, such as building a dike around the North Sea, reclaiming the Doggerbank or a row of barrier islands in front of the Dutch coast had been circling around for decades. Efforts to deal with clogging infrastructures on the mainland, the promise to conquer 'new land' in the sea appealed to the imagination of generations of policymakers, spatial planners, landscape architects and engineers. An airport in the sea, 90,000 houses, conference centres, hotels and many more economy-driven plans to cope with land-related issues were projected onto imagined reclaimed land in the North Sea. An interesting read is the collection of ideas and plans for coastal development and adaptations to sea level rise on the Public Wiki pages of Deltares. This collection of ideas is divided into six themes: 'create space', 'protection against the sea', 'living and recreation', 'nature and environment', 'fishing and agriculture', 'transport and energy'. Thus, the lack of including the arts, culture and heritage seems manifest.

However, a new dichotomy arose on the Delfland shoreline: New Land as opposed to Existing Land. In 1996, these plans resulted in public protests. 'Laat de kust met rust' (Leave the coast as it is) became the battle slogan, and Wim de Bie, writer and creator of satirical TV programs, danced in honour of his ancestors the 'Dance of the Cananefates' on the beach (De Bie et al, 1975). Public support for economic-driven seaward expansions vanished.

'The sea belongs to everyone and thus to no one' - words that not only define the world's largest public space but also leave it unarticulated. With 
this concept, Satellietgroep kicked off in 2006 with a fake news article 'Kunst beschermt kust' (Art protects coast). In anticipation of the future coastal expansions, the collective conceptually appropriated one of the artificial islands. In March 2006 the official opening is performed with a construction sign called 'Satellieteiland, where art is the first form of life' on the beach south of Kijkduin, where, years later, the Sand Motor is built. The opening act is performed by prof. dr. Ronald Waterman, esteemed ambassador of nature-based coastal expansions. (Haasnoot, M. (2019)

Around the same time, a tiny booklet called 'Kustboekje' introduced the next stage of coastal development with a so-called sand source, combining safety and spatial quality with a time horizon of fifty years (Adviescommissie Zuid-Hollandse Kust, 2006). Integrated coastal management became the keyword for combining coastal safety in the industrialised urbanisation of the metropolis with upcoming values for nature to achieve social feasibility. Restoring the shoreline of the 17 th century and so-called 'nature compensation' for previously lost nature reserves due to the expansion of the Rotterdam harbour, were depicted with images of pristine dunescapes and green shores to frame the coastal expansion as 'nature'. This booklet also promotes the 'Dutch Coast' as a product for the further development of tourism and recreation.

In 2011, the Sand Motor came to be. It was framed as 'nature', but is that what it is?

"I enjoy watching the sea from a distance. There is a double sea. The Laguna. The sea. This artificial beach has two horizons" noticed Yun Ingrid Lee, student of the ArtScience Interfaculty ElementsLab.

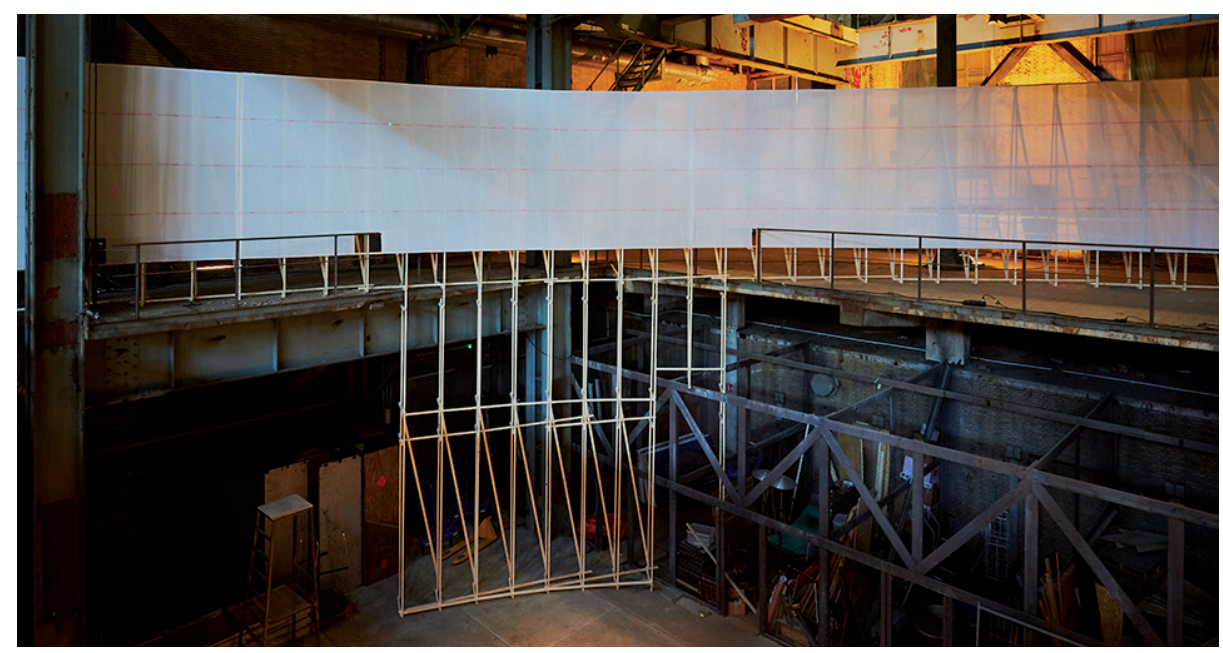

Figure 3. Maurice Bogaert, Wide / White, Climate as Artifact 2018, photo Johan Nieuwenhuize. 
In art history, a panorama was a way to imitate or simulate a landscape. The experience of a landscape or so-called 'nature' is not unambiguous, but subject to the spirit of the time. 'Wide / White' by artist Maurice Bogaert, created for the exhibition program Climate as Artifact in 2018, is a spatial intervention, an 'observation machine'. The panoramic installation draws the largest possible circle in space. It crosses open spaces and escapes obstacles along the way. The surface is translucent and white, and thus escapes the romantic illusion of projecting an idea of a landscape onto a pristine canvas. The visitor enters into an undefined film set and is invited to complement the art work with observations and subjective memories.

At the opening of the North Sea Conference 2014, minister Melanie Schultz van Haegen (Ministry of Infrastructure and Environment) stated: "The Dutch coast is our national heritage". At the same conference, Satellietgroep presented the Sand Motor as a cultural phenomenon and initiated the first consistent artist-in-residency and public program with the Sand Motor. Redefining the Sand Motor as a cultural phenomenon, brings the Sand Motor into the realm of art, culture, and heritage. With the Sand Motor, all issues about climate change, sea level rise, the future of coastal safety and the role of humanity in these processes come together. As Jegens \& Tevens commented in their online art magazine: "Building with nature' it is called affectionate$l y$. From the first moment the natural violence involved in this cooperation between man and nature has proved to be a great source for researchers and scientists, but also for artists. The Satellietgroep Foundation understands this and offers a selection of artists the opportunity in the coming years to work with the Sand Motor through an artist-in-residency program."

Without judgement, without a preconceived idea, Satellietgroep is curious to see the opportunities that climate (change) can offer us.

\section{Sand Motor as ephemeral Land Art}

'Land Art' is an important international movement in the arts. The book 'Destination Art' (2006) by art historian Amy Dempsey is a critical guide to a selection of two hundred of the most important modern and contemporary art sites around the world and is regarded worldwide as the 'art lovers travel guide'. It provides an interesting read of how artists, since the sixties, express the interrelations of humanity with nature. The book includes a few famous Land Art works in public space in The Netherlands. One of them is 'Hemels Gewelf' (Celestial Vault, 1996) by American artist James Turrell, created in the artificial dunes of Kijkduin: "A place where you have the sky to yourself, where you can practice the art of seeing" Lily van Ginneken, director of Stroom, The Hague Contemporary Art Center, wrote about Celestial Vault. 
Working with, instead of on the Sand Motor may require all the sensitivity and knowledge we can imagine. In that sense, the Sand Motor can be perceived as a staged landscape, as a stage projected into the North Sea. Built on the foreshore of the oldest dunes in The Netherlands. It provides us with the unique opportunity to stand in the middle of the sea, some twelve meters above the former sea bottom of 2011. To stand and look over the shoulders of our ancestors, who probably last stood there around the year 1600. And while being surrounded by the sea and elements, the Sand Motor provides a look back at the shores to rethink time and space in the past, present and future. It is said to be the first constructed seascape in the Netherlands that is built outside the dikes with the purpose to change and even dissolve into the sea, beach, and dunes. It did not exist, and it will dissolve. But will it really be gone, or has it transformed into something else?

Sixteen Public Expeditions, a growing Sand Motor Collection, and the exhibition program called 'Climate as Artifact' demonstrate how an explorational artist-in-residency program and an inclusive public program can target alternative ways of perceiving and being in the Sand Motor. How does art and redefining the Sand Motor as a cultural phenomenon generate a more essential understanding of the Sand Motor?

"The human desire to understand abstractions leads to new inventions, critical research, and a poetic contemplation of our environment", Heske ten Cate, artistic director of exhibition space Nest The Hague wrote. How can we relate to the abstract dimensions of the Sand Motor? The Sand Motor, as a wide open and seemingly empty stretch of sand positioned just next to one of the most densely populated areas of Europe, offers itself as a blank slate in which experimental works of art engage with open space, the natural elements and the public as pioneers. Can the Sand Motor be perceived as ephemeral Land Art? A time-machine that transports us from the geological era of the Holocene to the Anthropocene, the current era in which humanity affects the earth as a geological force? An unarticulated new wilderness? Or, as urbanist Jan de Graaf questions, is it a suicidal landscape?

\section{Public Expedition Sand Motor \#1 Sand Drift, November 2014}

Zoro Feigl is the first artist-in-residence of the Sand Motor program in 2014. While roaming the Sand Motor and discussing the moon and stars with coastal morphologist prof.dr.ir. Marcel Stive, Feigl reflects on the Sand Motor in the context of Land Art and the artwork 'Spiral Jetty' (1970) by American artist Robert Smithson: "As a piece of Land Art, the Sand Motor is of course a wonderful work. The work such as 'Spiral Jetty' was intended. Land Art to give back to nature. Not something that needs to be preserved, but something that is constantly 
changing. Playing with this nature is what I like to work with. A constant dialogue between material and natural laws. Preferably a wild conversation in which the various parties try to convince each other with some force. Often a lost battle for me, nature conquers, it never gives up. In fact, we only give the sea a pile of sand to play with ... to spread it out over the coast. We look at how the sea approaches that, hoping to learn something from it, or to enjoy the beauty it produces."

Feigl is fascinated by why things work the way they work, why something moves the way it moves: "On the Sand Motor I had a work in mind, something that could compete with this sand plain, a work that could enter into a conversation. In the many walks there I noticed that the small details in this wild-water desert fascinated me the most. The patterns in the sand, the waves. The drawings that the wind and water make. The size became an obstacle. That's how I started to highlight and isolate the pieces that fascinated me. Playing with these small things eventually became the artwork 'Untangling the tides' with two ropes, the ends of which are attached to small revolving motors, creating a hypnotic effect."

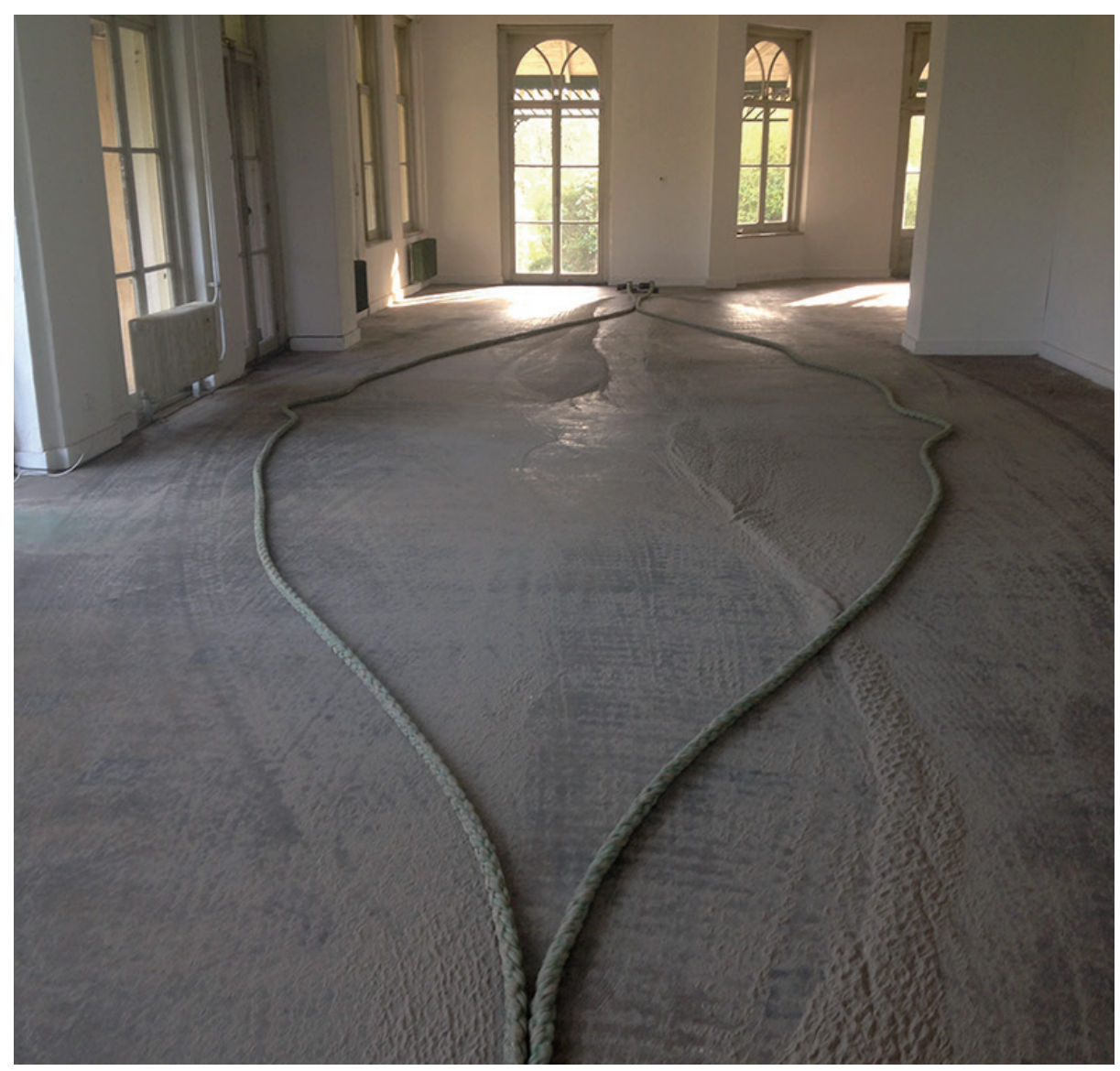

Figure 4. Zoro Feigl, Untangling the Tides, Public Expedition Sand Motor \#1 Sand Drift, Villa Ockenburgh November 2014, photo Thijs Molenaar. 


\section{Working with the Sand Motor}

The idiom of the arts is not language itself, but to evoke our imagination and appeal to individuals and audiences by sensory experiences. One of the conditions for artistic field research is that the public must be able to participate and share in the findings. Being outside, out of your own comfort zone, is one of the experiences the Sand Motor provides as a cultural phenomenon.

Starting in September 2015, Satellietgroep engaged for a year in the ElementsLab with lectors, students, and invited experts to enhance the scope of artistic fieldwork on the Sand Motor as part of the ArtScience Interfaculty program of the Royal Academy of Arts The Hague i.c.w. Leiden University. This interdisciplinary bachelor's and master's program fosters curiosity-driven research as an approach for the making of art: "The Elements is an outside coastal lab situated along the North Sea at the Sand Motor south of The Hague. What does it mean to work in a dynamic intertidal environment, where the tides are dictating time and seasons are close to our skin? The lab has a phenomenologist approach, stimulates students to play, wander, explore, and focus on elements in their own way, where also their own sensorial body in relation to this dynamic landscape can be considered as an element."

Aisha Pagnes, student of the ArtScience ElementsLab reflects: "The quintessential purpose of the ElementsLab is to take you out of your element and into the Zandmotor's. At times, a rather discomforting practice, but most importantly, a reminder for how complacent we have become in our planned safety, how we have forgotten to intuitively and respectfully engage with nature and anything that does not fit our scale or schedule. The Sand Motor has a time of its own. Emails and appointments become ludicrous here. Bettering oneself and franticly huffing up the ladder of self-improvement and recognition becomes redundant. You may however, sit and smile, ignorantly and simply."

Public Expedition Sand Motor \#6 Climate Experiment, December 2015 Artist-in-residence Esther Kokmeijer explores the scope of human resilience and climate adaptivity. She organised a climate experiment at the Sand Motor during the 2015 Winter Solstice, marking the shortest day and the longest night. Led by several experts, a select group of 15 invitees experienced, embraced, and questioned extreme cold and heat to their bodily limits. Among the experts invited were landscape architect Dirk Sijmons, co-inventor of the Sand Motor, Jurjen Annen, who led a cold training, Mark Hoek, who initiated a heat ritual in a sweat lodge and volunteers of the coastal Rescue Brigade. The experiment is documented with a thermographic camera and an infrared wildcam. 


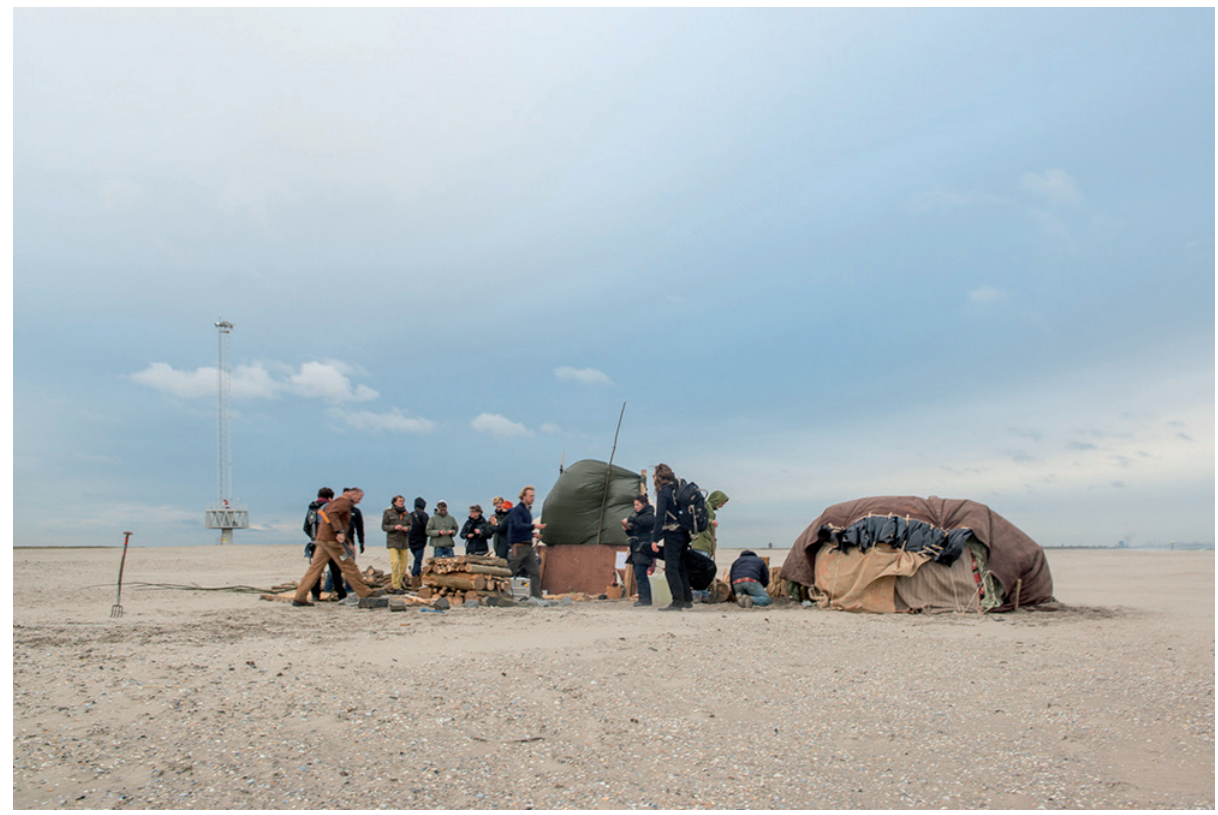

Figure 5. Esther Kokmeijer, Public Expedition Sand Motor \#6 Climate Experiment, December 2015, photo Esther Kokmeijer.

The arts can express the spatial, social, and ecological qualities - as well as the problems - of our coastal areas and make them engagingly accessible to the public. These works can transform a destination normally characterised by consumption and recreation into a platform for critical communication and serious reflection. This timely reflection on spatial transition processes may act as a strong catalyst in generating public and professional discussions and connect contemporary research and new works to historic and future works and coastal transitions. Satellietgroep explores the Sand Motor from an artistic perspective and reflects on it in the context of ongoing artistic field research in Scheveningen, polders, the Wadden Sea, Afsluitdijk, and international exchange projects.

Commissioned by the Province of South Holland, Satellietgroep created a cultural vision of the Sand Motor. The collective emphasised that perception, experience, and imagination allow societal access to knowledge and skills, and wrote: "This can be achieved by positioning the Sand Motor in the middle of society. Transdisciplinary imagination and insights are combined during the public program. The projects place experts and laymen on an equal footing, whereby professional and personal identity shifts to the background and a collective experience arises. The rugged environment of the Sand Motor ensures an adventure with the dynamic concept of man-made nature. It is a space where a public expedition can take place in the middle of a sandstorm, and where people come closer to each other during a cinema event under the moonlight. It is an area where artists, scientists, 
policy makers, visitors and residents, young and old, experience something that they will not soon forget. This creates a personal and sensory connection with the public research area, creating an intimate commitment and strengthening the relationship between people and nature. In short, the public program makes the interconnectivity of people and nature accessible and visible. Laymen and experts are thus part of the discourse on sea, ongoing climate change, and coastal transitions. Societal inclusiveness in these developments increases the resilience of people and/with the coastal landscape."

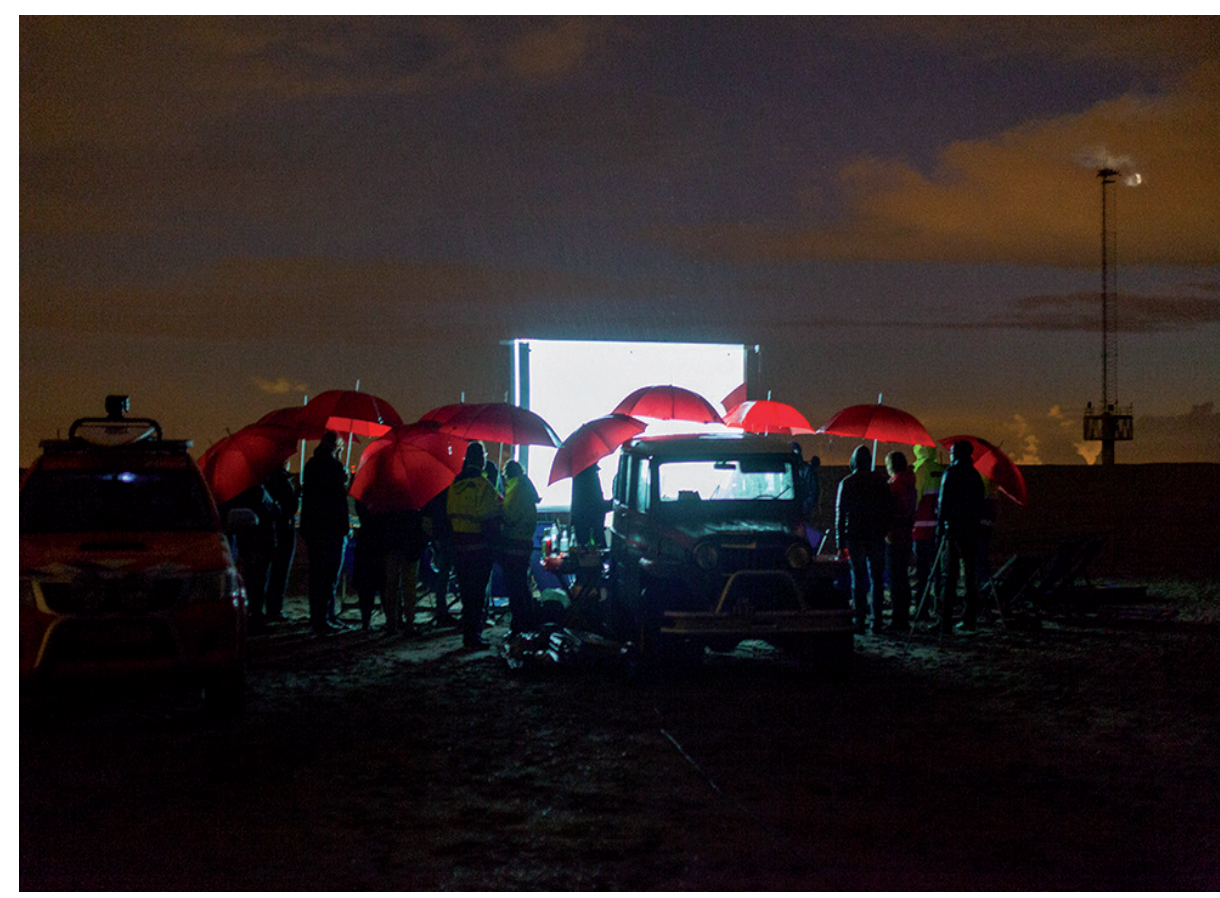

Figure 6. Laboratory for Microclimates, Zand Zicht, Public Expedition Sand Motor \#5 CineMare at Sand Motor, September 2015, photo Florian Braakman.

Faced with images of suffering polar bears far away, we may wonder if the effects of climate change can be noticed in our daily environment. How close to our bodies is climate change and how we can learn to position ourselves in these transitions for the coming future? One of the conditions humans and other species need to survive is fresh water.

\section{Public Expedition Solleveld \& Sand Motor \#10 Water Pioneers,} December 2016

Satellietgroep i.c.w. Onkruidenier invited the public to join a walk through a time line of 10.000 years coastal landscape history.Together with experts in hydrology, archeology, ecology, Dunea (dune drinking water), and NatureCoast, the public learn from drinking water makers and nature experts, 
discover old parcelled fields and archaeological traces of coastal civilization in Old and New Dunes, listen at the Duindijk (dune dike) how the watershed was moved during the construction of the Sand Motor, walk on the innovative Sand Motor as a 'Water Maker' due to the growing freshwater bubble underneath, to the North Sea under which fossil water is hidden. Posing as Climate Tour Guides, the artists offered the participants at five locations the taste of the old and new coastal landscape, questioning if we can taste climate change.

Tastings Water Pioneer:

1. Water tower: malted barley bread with a puree of broad beans and Juniper berries from the old layers of Solleveld accompanied with a Pine needle infusion.

2. Before the walk we share little bottles of salty water that corresponds with the salinity of our own body and lies around $4 \%$. This is a saline solution between our body and the sea, in order to prepare ourselves to the tradition of salt cures.

3. Watershed: a schnapps of wild roses from the dunes or a lost green walnut liquor together with a marshmallow made from the marsh-mallow root.

4. Sand Motor: The Water Fountain, with the taste of the freshwater lens from the Sand Motor.

5. Tasting at sea: a fossil bite of diatomaceous earth (compacted earth from diatoms) with a crip layer of seaweed salt.

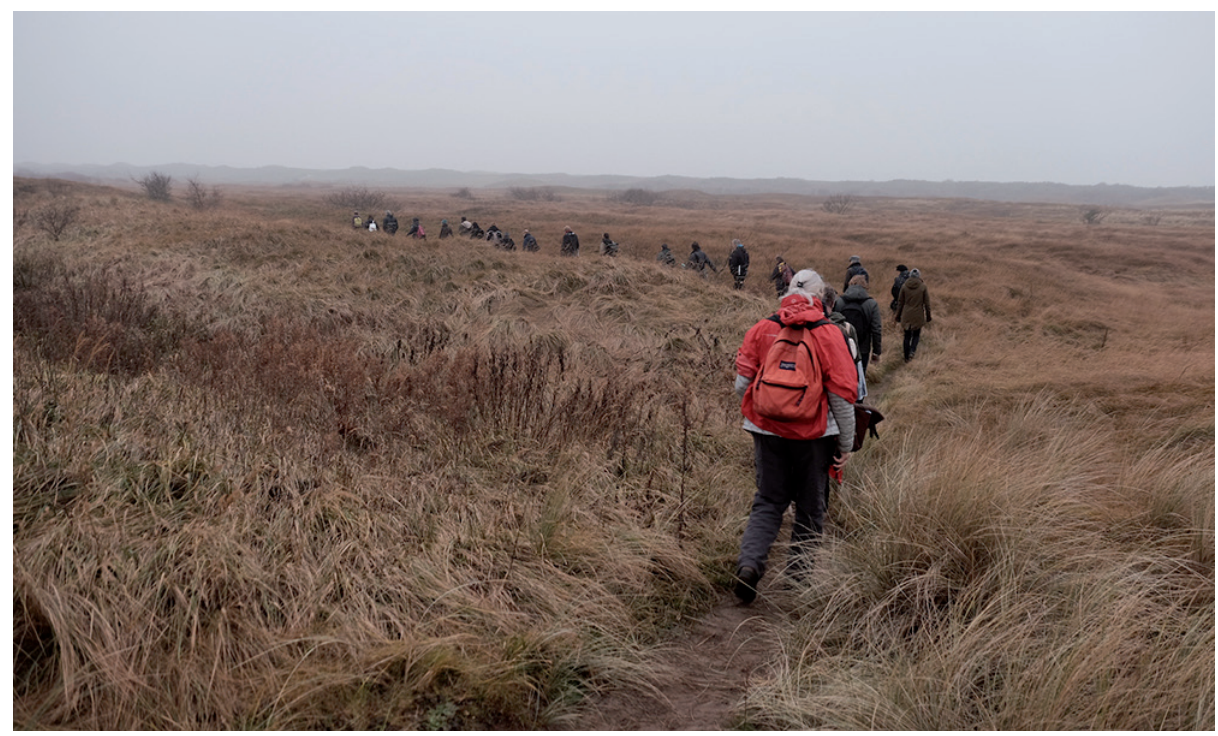

Figure 7. Walking a time line of 10.000 years coastal landscape history, Public Expedition Solleveld \& Sand Motor \#10 Water Pioneers, December 2016, photo Theo Mahieu. 


\section{Climate as Artifact}

Following the insights derived from the art program with the Sand Motor, in 2018 Satellietgroep posed the question 'Who is nature?' (Satellietgroep et al., 2018) and developed the public exhibition program 'Climate as Artifact'. Materialising ideas through the arts by including scientists and the public, while redefining climate as an artifact (as something we make), helps to increase our sensitivity and to see connections within the natural world and between our actions and our environment.

As an immersive experience of Sand Motor, art student Flora Reznik dug a hole for eight months. 'Hole' became her graduation work of ArtScience Interfaculty and Reznik reflects: "The work had as a point of departure - a long durational performance in which I dug a hole for eight months in an artificial beach. I followed a strict set of rules: I must go once a week with basic equipment and dig as much as I could during the few hours of light that the Dutch winter provides. I challenged my body at the same time I took measures to care for it: the task became to make a place for myself, a shelter. I engaged in a conversation with the wind: it was clear that we were both the makers-unmakers of the hole. The few passers-by in that far off place saw at a distance a figure at work, and they would approach me. As if they were scripted, everyone asked the same question: 'what are you doing?', although they could clearly see what I was doing. I refused to give reasons. So very interesting, honest and intimate conversations occurred in that isolated location after overcoming the first impulse of people to possess explanations. I realized I had an uninvited audience, that what I was doing wasn't just an action, but a performance."

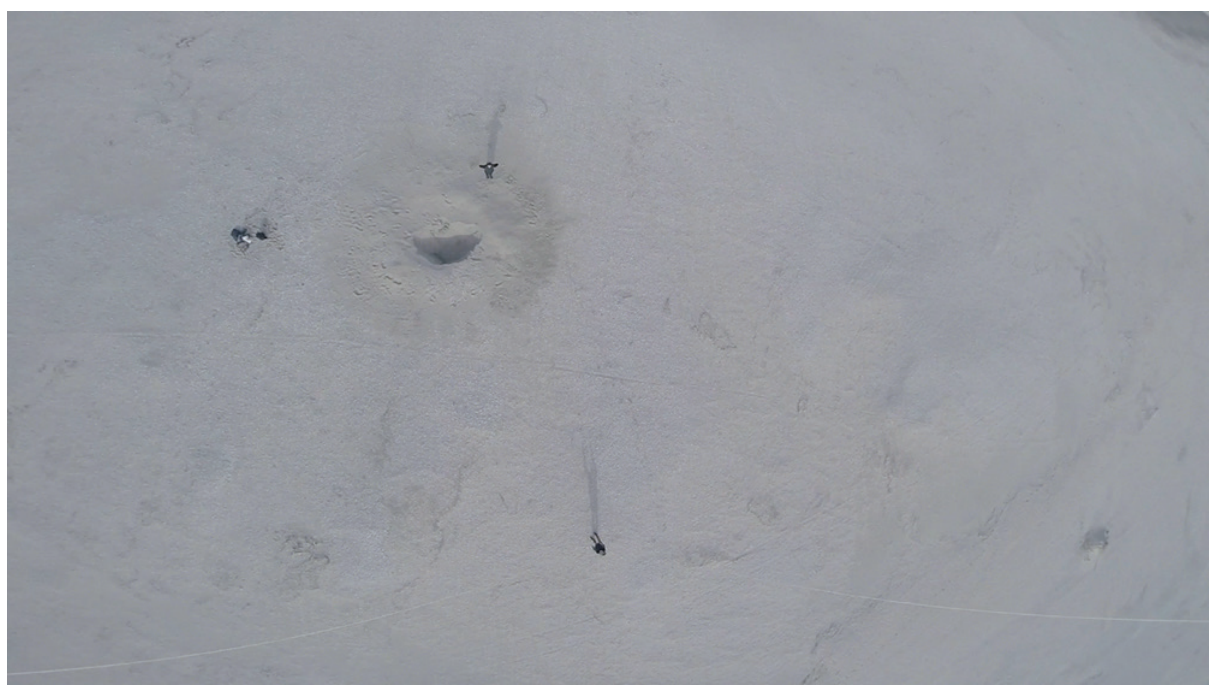

Figure 8. Flora Reznik, Hole, ElementsLab ArtScience Interfaculty 2015- 2016, photo kite shot of Hole. 
Perception, experience and imagination allow societal access to knowledge and skills. Faced with current and future challenges, the time-depth of landscapes and of ourselves, we need a new visual idiom, other collaborations, and multi-facetted perspectives. In sync with the current global timeframe, we may need to dissolve superimposed differences between sea and land, culture and nature, arts and sciences, professionals and general audiences to learn together where we come from and where we are going. While in the process of expressing unarticulated values, a new visual language is invented, often inspired by the poetic idiom of palaeontologists, geologists, archaeologists, hydrologists, coastal morphologists, oceanographers, climate scientists, ecologists, philosophers, etc., who engage in these adventures and share their insights. Aimed to enhance a deeper professional and public understanding. The network evolved in an extended family that includes the sea, shores, and the Sand Motor as valued non-human entities.

One of the most challenging aspects of the arts is the ability to pose different questions. In January 2006, Satellietgroep kicked off with the question 'To whom belongs the sea?' To celebrate over 12 years of pioneering and to prepare for an unforeseen and challenging future, in January 2018 they started to rethink our perceptions of culture and nature with the question 'Who is nature?' Satellietgroep invited seventeen artists and designers - all previous artist-in-residents - to jointly create a public program based on shared fascinations. This developed into an exceptional project, namely the exhibition program called 'Climate as Artifact'. For the first time, climate is emphatically positioned in the cultural domain. In the run-up to the autumn exhibition, monthly informal meetings took place with the participating artists and special guests from different domains. In addition, a supporting program evolved, where artists in smaller group presentations tested their artistic research with the public and entered into dialogue with scientists, philosophers and each other. Following the practice of Satellietgroep as an alternative academy and appreciating the sea and shores as vital learning environments of time and space, the visitors had the opportunity to engage with the artists who worked on-site, contribute to the ongoing process of artistic research, share their insights, and discover, through the arts, a multitude of fields of knowledge. Experts in the fields of nature, climate, geology, archaeology, oceanography, philosophy, zoology, botany, and spatial planning - as well as a canoe builder from the Marshall Islands - actively contributed to the making of new artworks and public dialogues. This method also led to an exhibition program that differs from more traditional exhibitions. It is closer to a sensorial knowledge lab; a space for experimentation, discussion and wonder; a workshop, learning centre and meeting place, where all your senses are claimed. 


\section{Climate as Artifact, 2018}

'Eighteen Coffee Breaks - Eight Working Hours' is a triptych composed by artist Maurice Meewisse. He explores the relationship between the landscape, the local, and social history of the Sand Motor. The work is inspired by the creation of this hybrid landscape and aims to bring it back to a human scale. The Sand Motor is, in a way, an accomplishment of industry, the result of human endeavour even though it is experienced as nature. Meewisse introduced the coffee break, a very important daily ritual.

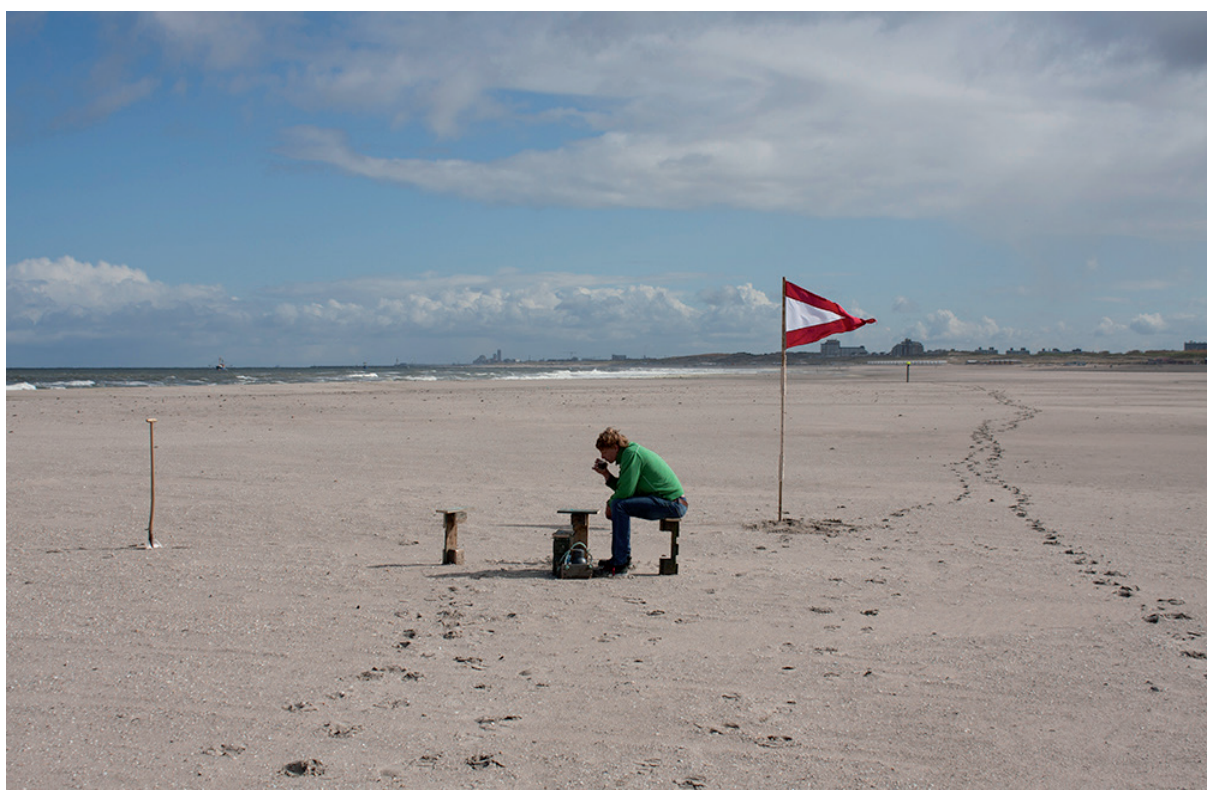

Figure 9. Maurice Meewisse, Eighteen Coffee Breaks - Eight Working Hours, Climate as Artifact 2018, photo Jacqueline Heerema.

\section{Destination Coast: Kijkduin}

Nowadays, two travellers from around the world seek the shores of Kijkduin: the one in search of art visits the famous Land Art work by American artist James Turrell, called 'Celestial Vault'; the other in search of coastal innovation visits Sand Motor. Sometimes they merge, in search of what the collective calls 'Destination Coast'.

Building on three years of experience as a nomadic arts initiative (Satellieteiland, 2006-2008), in the summer of 2009 Satellietgroep built Badgast. In the middle of a temporary urban surfing village called F.A.S.T (Free Architecture Surf Terrain, Scheveningen), the collective initiated an artist-in-residency and public program (Badgast, 2009-2015) in one-and-a-half stacked 
re-used shipping containers, designed by Refunc Recycle Architects. During five successful years of exploring the scope of the sea with this international artist-in-residency program, cinema at sea and talks at Badgast, and an international exchange program called 'Now Wakes The Sea' (since 2012) Satellietgroep built an extensive network and expertise of interconnecting arts, science and society on coastal transitions and climate change, in The Netherlands and abroad.

Meanwhile, construction plans for the Sand Motor evolved, thus providing a new opportunity to create an inclusive program to enhance climate-consciousness. Though local public protest against the construction of the Sand Motor prevailed in 2011, with the building of the Argusmast observation tower in 2012 in the middle of Sand Motor, public protest arose against building in 'our nature area', thus showing a remarkable shift in public opinion. Dutch artist-architect John Körmerling designed the Argusmast with a public viewpoint. But Rijkswaterstaat never allowed the public to visit the Argusmast. Abe Veenstra, Advisor of Spatial Quality for the Province of South Holland (2013-2016) reflects, in 2013, on the Argusmast: "It underlines the laboratory character of the place; playing with sand and water elevated to science. However, it is only the Argus eyes of the scientists who are allowed to view the (undoubtedly) beautiful view. I consider it a missed opportunity that the placement of such an object has not been used for a combination with a public viewing point where it can literally be illustrated how the fascinating game of sand, wind and water is played here."

Students of the Sand Motor ElementsLab comment on the Argusmast: "During the time we spent on site we discovered that in certain weather conditions, the mast becomes an elements-driven sound instrument - an aeolian harp of sorts."

"The Dutch are masters in disguising a cultural landscape as a natural one. We tend to design, construct, reconstruct nature to fit our need" reflected Satellietgroep. This ongoing friction between the top-down framing of the Sand Motor as 'nature' and the societal challenges of sharing insights of human-induced coastal interventions is expressed by Ronald van den Hoek (et al., 2014) in 'Uncovering the origin of ambiguity in nature-inclusive flood infrastructure projects, Ecology and society': "Our main finding was that ambiguity in Building with Nature projects seems to originate from a contradiction between the beliefs held by different actors. Furthermore, our results suggest that in the current practice of Building with Nature projects, the scientific knowledge of experts is perceived as more legitimate than the local knowledge and experiences of lay actors, which implies that experts have a more powerful position in multi-actor decision making. Thus, our research underlines the difficulty of bringing local knowledge and past experiences of lay actors into collective decision making." 


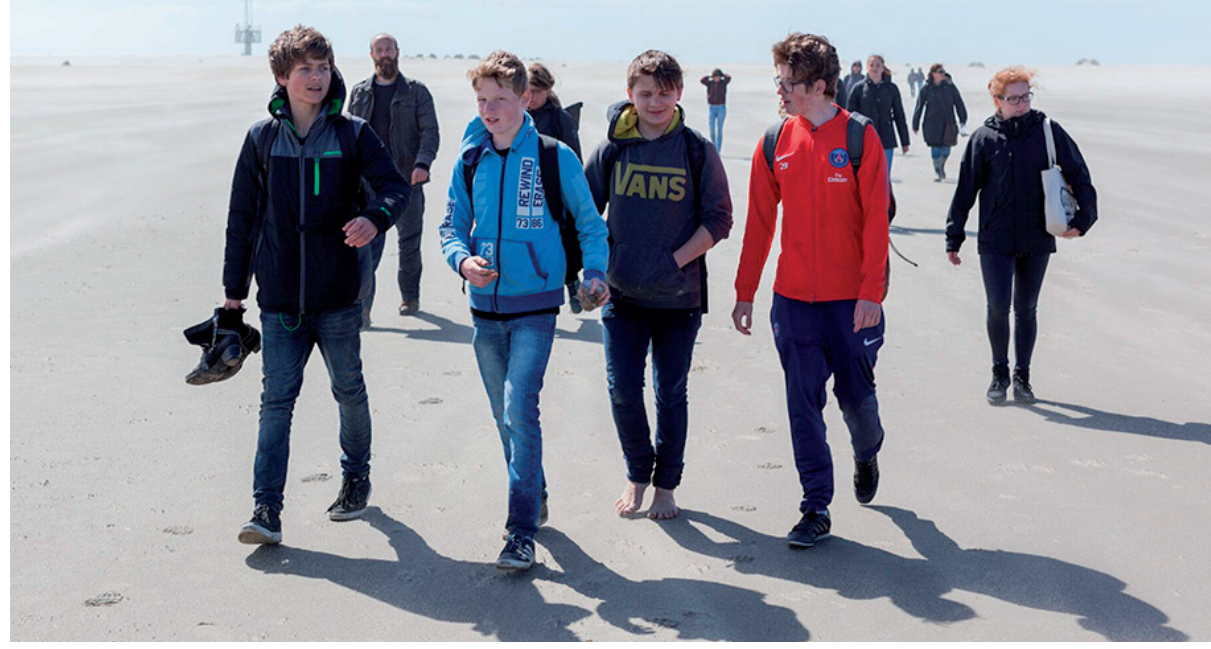

Figure 10. Sand Motor as learning experience for public climate-consciousness, Public Expedition Sand Motor \#14 Timescale of Landscape, April 2018, photo Florian Braakman.

"Dears, storm today: so great for filming, and possible some rain; no worries, I made a shelter for us this morning and prepared another experiment. See you there at 14:0o" as Cocky Eek, artist-tutor of ArtScience Interfaculty texted to the students of the ElementsLab. Challenged by the ongoing artistic field research and public expeditions program, the need for a modest, sustainable and inclusive Sand Motor 'shelter' arose. A space to explore, collect, share and learn on-site from the ongoing outdoor artistic and scientific experiences, with the Sand Motor and with the public.

Commissioned by the Province of South Holland and together with public and professional stakeholders, Satellietgroep worked in 2014 and 2015 to develop Zandgast, the proposed new educational Sand Motor visitor centre, with an artist-in-residency and public program on and about the Sand Motor. A modest but visionary space, with the aim to collectively share all works and insights on location with a wider public audience to enhance climate-consciousness. Overtreders W, Rob Sweere and RAAAF (Rietveld Architecture-Art-Affordances i.c.w. Atelier de Lyon, Deltares, TU-Delft, Volker Wessels) were selected for the first designs of Zandgast. During several stakeholder meetings, the proposed designs for Zandgast achieved general support. 
The proposal by RAAAF involves a next innovation of building with sand. With locally-sourced sand and the use of biological methods (Beach Rock, TU Delft et al.), this contemporary architecture will, in time, erode, as the Sand Motor does, thus bringing the sand back in the environment.

Henk Ovink, 1st Dutch Water Envoy commented on the design proposal of RAAAF: "The pavilion is the first real experimental upscaling of building with sand that RAAAF | Atelier de Lyon performs i.c.w. Deltares, TU-Delft, Volker Wessels. The quality of our country and landscape, of our cities, starts with the right match between safety and quality and it is that match that RAAAF | Atelier de Lyon embraces and is committed to a future perspective: temporary and adaptive, robust and natural, innovative and inspiring. The imagination speaks and makes the safety of our country really tangible in this sand pavilion." Eric Luiten, Advisor of Spatial Quality for the Province of South Holland (2009-2012) added: "Sustainably manufactured, explicitly architectonic, merges with the harsh environment. Very delightful. Robust, manageable, tenable in harsh conditions and at the same time understandable as temporary. Uncommon, stubborn, interesting."

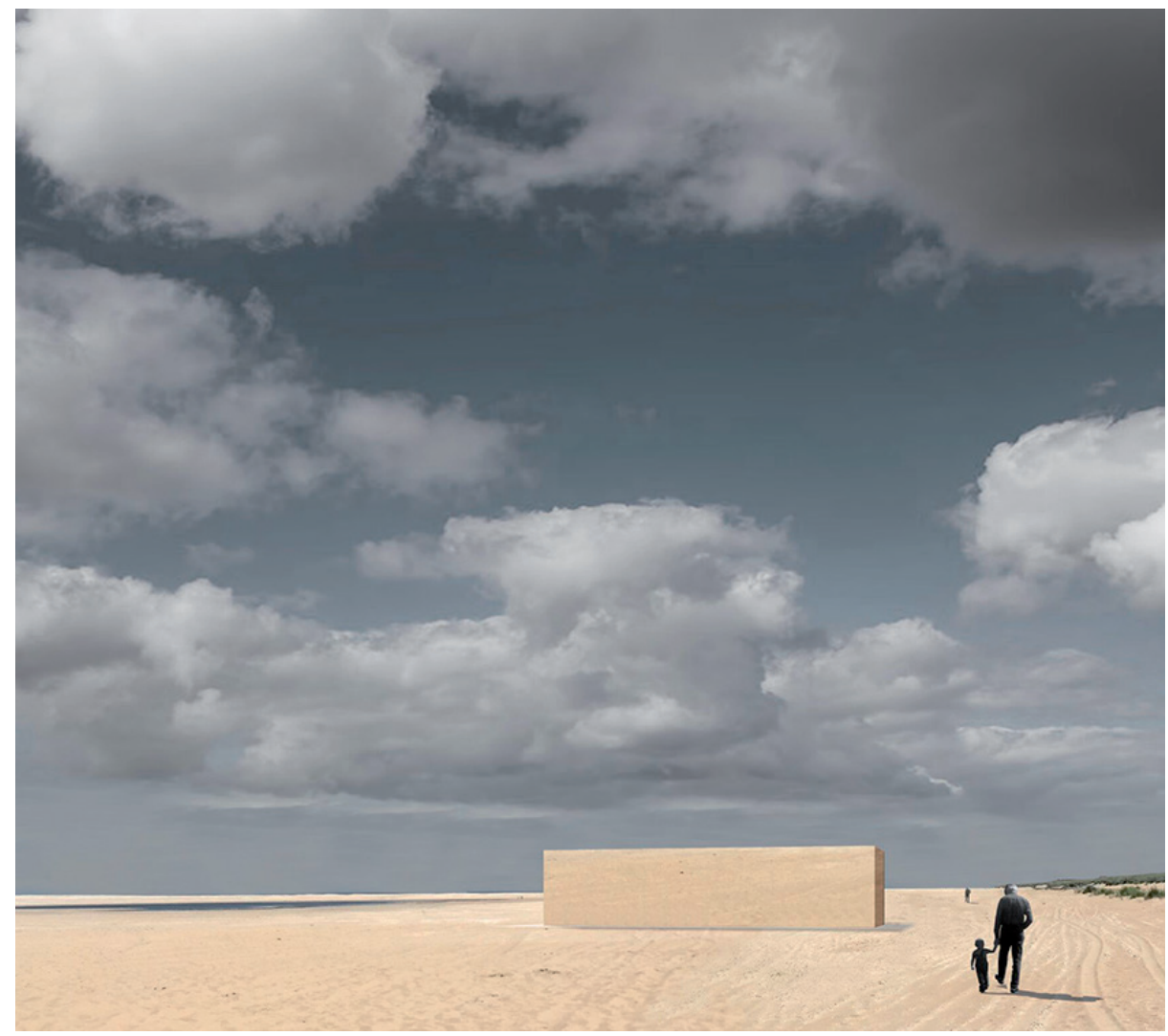

Figure 11. RAAAF, Rietveld Architecture-Art-Affordances i.c.w. Atelier de Lyon, Deltares, TU-Delft, Volker Wessels, proposed design Zandgast, 2015. 
However, in December 2015 minister Melanie Schultz van Haegen (Ministry of Infrastructure and Environment) stated that the safety of the Dutch coast is in order, and it is now time to start building on the shores for economic and tourist growth. Again, societal protest as 'Laat de kust met rust' arose, and a 'Kustpact' was developed. While commercial exploitations with rows of holiday houses on the beaches continues, the only cultural initiative called Zandgast became collateral damage.

Although the physical materiality of the Sand Motor is impressive, the experiences of art will survive in the collective public memory, after the Sand Motor has dissolved. In 2015, artist-in-residence Theun Karelse offered the audience 'Fossils Soup'. On September 6, 2019 world famous artist Olafur Eliasson (Iceland, Denmark) re-posted on Instagram - in the context of his solo exhibition called 'In real life' (Tate Modern, London 2019-2020) - to his 407.000 followers:

\section{Public Expedition Zandmotor\#2 Cultural Geology, March 2015}

" $\mathrm{K}$ is for Kitchen. When eating a bowl of fossil soup, one might ask oneself, is this a vegetarian dish? Are fossils considered animal remains, or geological objects? A few years ago, Dutch artist Theun Karelse was invited by the Hague-based Satellietgroep as an artist-in-residence on the Sand Motor - a giant artificial sandbank running along the coast of the Netherlands. Quite unexpectedly, he ended up gathering a sizeable collection of fossils, which had been deposited along with the sand from the North Sea floor. Theun wrote: 'Some of these fossils are rather spectacular, like a mammoth rib or the tooth of a woolly rhino. These date back to the last glacial maximum (Ice Age) and are between 40,000 and 20,000 years old. There are also some less spectacular bone fragments.

It is pretty amazing to find these objects and hold them in your hand. It made me wonder if they grant access in some way back to the ancient past. Can anything from those times be experienced through these bones? Would they perhaps still have a taste? This became an experiment to see if we could become the first people in many thousands of years to taste mammoth!' He decided to approach experts in prehistoric food and archaeological cuisine to experiment in making a fossil broth, first by simply mixing the bone fragments with water and stewing them. This was then developed into a recipe for 'mammoth soup': assorted Sand Motor fossils, water, freshly picked ramson (daslook, or Allium ursinum), birchwine (berk, Betula), fermented cornel (kornoelje, Cornus mas), raw reindeer meat (rendier, Rangifer tarandus). Archeological experts confirmed that because fossils of this age still can contain traces of cartilage, marrow, and certainly DNA, the soup is not, in fact, vegetarian." 


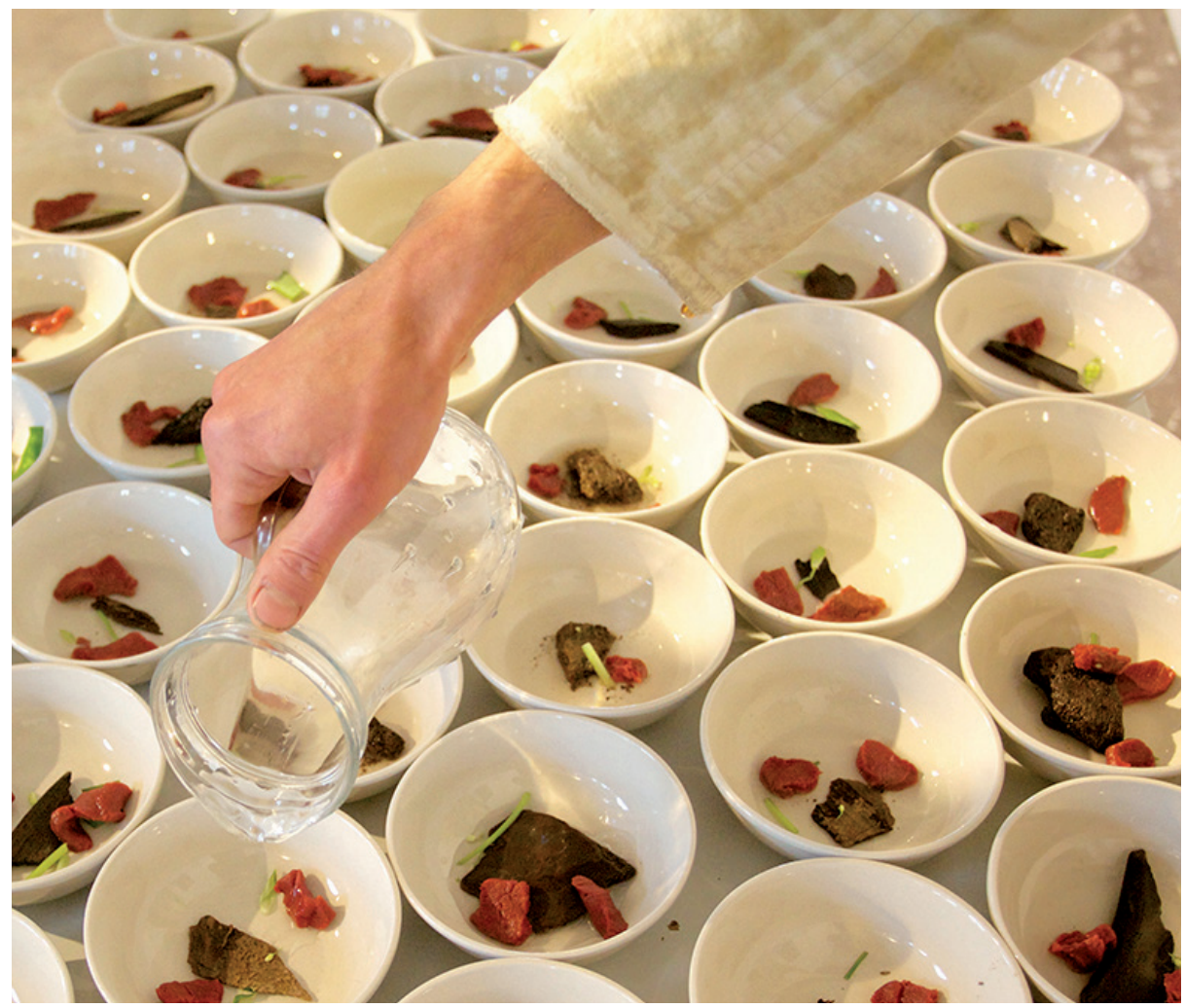

Figure 12. Theun Karelse, Fossils Soup, Public Expedition Zandmotor\#2 Cultural Geology, March 2015, photo Florian Braakman.

\section{Conclusion}

The Sand Motor did not exist and, due to the predesigned ephemeral character, it will dissolve. But will it really be gone or has it transformed into something else? As the first of its kind, and with the transformation of building with nature into Building with Nature (written in capitals), some unforeseen lessons are learned with the Sand Motor. What are the lessons learned so far?

With ongoing climate change, anthropogenic interventions in the coastal landscape will increasingly influence choices for a safe and healthy living environment. With the construction of Sand Motor, a new opportunity emerged to create an inclusive cultural program to enhance professional and public climate-consciousness.

The Sand Motor is a man-made coastal intervention in public space, an open-air and publicly-accessible research site. It uses the forces of the wind and waves as active agencies of change. This essay argues, that as cultural phenomenon, the Sand Motor is a driving force for humanity to change. 
The ephemeral nature of the Sand Motor itself challenges a polyphonic discourse for the co-creation of experiential knowledge. It evolved from a non-place into a vital learning environment for the cross-pollination of ideas and experimentations to rethink the reciprocal relations of humanity and nature in past, present, and future. The projects by Satellietgroep instigated a public dialogue on the unforeseen values of Sand Motor and the relationship between nature and people. However, the missed opportunity of the Sand Motor is an on-site space, to explore, collect, share and learn from the ongoing outdoor artistic and scientific experiences, with the Sand Motor and with the public. In that sense and for the future, it is essential to solve the ongoing friction of top-down framing of the Sand Motor as so-called 'nature' and target the societal challenges of sharing insights of human-induced coastal modifications in cultural public space.

We conclude that, for the evolution of Building with Nature as challenge to rethink culture and nature in coastal landscapes, it is vital not only to include nature, but also culture. Therefore, pioneering with the Sand Motor should also include pioneering with the social and cultural values, to enhance not only public and professional climate-consciousness, but also to adopt it as a human-inclusive landscape. This may well be the most important lesson learned for a more inclusive societal embedding of the concept of Building with Nature in general.

\section{Acknowledgements}

With special thanks to all team members and board of Satellietgroep since 2006, the artists, designers, students, pupils, visitors, local and scientific experts, partners and funding organizations who engaged with the programs and made these pioneering adventures possible. 
Selected artworks

Bogaert, M. (2018). Wide / White

De Kroon, P-R. \& De Kroon, M. (2003). Hollands Licht.

Dempsey, A. (2006). Destination Art

ElementsLab $(2015,2016)$. ArtScience Interfaculty

Feigl, Z. (2015). Untangling the Tides

Karelse, T. (2015). Next Doggerland, Fossils Soup

Kokmeijer, E. (2016). Climate Experiment

Meewisse, M. (2017, 2018). Eighteen Coffee Breaks - Eight Working Hours

Reznik, F, (2016). Hole

Smitson, R. (1970). Spiral Jetty

Smitson, R. (1971). Broken Circle / Spiral Hill

Stroom et al (1960). Hemels Gewelf in Kijkduin / Celestial Vault in the Dunes 
Adviescommissie Zuid-Hollandse Kust. (2006). Kustboekje - groeien naar kwaliteit. Provincie Zuid-Holland.

Augé, M. (1992). Non-Places: An Introduction to Anthropology of Supermodernity. Le Seuil.

Couling, N. R., \& Hein, C. M. (Eds.). (2020). The Urbanisation of the Sea: From Concepts and Analysis to Design. Nai010 Publishers. https://doi.org/10.7480/isbn.9789462085930

de Bie, W., Dekkers, W., Dorrestein, R., Huf, P. E. B., van Praag, M., Wolkers, J. (1997). Laat de kust met rust [Leave the coast in peace]. Bas Lubberhuizen.

Haasnoot, M. (2019). Plan Waterman - KustWikldee - Deltares Public Wiki. Deltares. https://publicwiki. deltares.nl/display/KWI/1.2.1.1+Plan+Waterman

Mintern, S. (2011). The Sand Engine as a Productive Void. Discussing the Spatial Value and Public Appropriation of the Sand Engine. TU Delft

Neefjes, J. W. P. M., Bleumink, J. A., Spek, T. (2018). Landschapsbiografie Nationaal Park Hollandse Duinen. Rijksdienst voor het Cultureel Erfgoed, \& Staatsbosbeheer.

Satellietgroep. (2007). S.MAG\#1. Sea Magazine. https://issuu.com/jacquelineheerema/docs/s.mag_1

Satellietgroep. (2008). S.MAG\#2. Sea Magazine.

Satellietgroep. (2013a). Badgast. Satellietgroep.

Satellietgroep. (2013b). Now Wakes the Sea. Satellietgroep. https://issuu.com/jacquelineheerema/docs/ now_wakes_the_sea

Satellietgroep, Bosman, L. \& Heerema, J. (2018). Who is nature? The Urbanisation of the Sea.

Satellietgroep \& Heerema, J. (2019). Sand Motor a cultural phenomenon. In A. Luijendijk, \& A. van Oudenhoven (Eds.), The Sand Motor: A Nature-Based Response to Climate Change: Findings and Reflections of the Interdisciplinary Research Program NatureCoast. Delft University Publishers.

Sijmons, D. (2015). Bewogen Beweging: Landschap onder de kap. TU Delft. http://www.hnsland.nl/media/ filer_public/e2/4c/e24cc6ef-57fa-4c52-b8d6-5976858eedf2/bewogen_beweging_nl_def.pdf

van den Hoek, R. E., Brugnach, M., Mulder, J. P. M., \& Hoekstra, A. Y. (2014). Uncovering the origin of ambiguity in nature-inclusive flood infrastructure projects. Ecology and Society, 19(2), 51. https://doi. org/10.5751/es-06416-190251

Vos, P. (2015). Origin of the Dutch coastal landscape: Long-term landscape evolution of the Netherlands during the Holocene, described and visualized in national, regional and local palaeogeographical map series. Barkhuis. 